\title{
Direita, volver: o governo Piñera (2010-2014) e a promoção do “Cisma do Pacífico"
}

Right face: the Piñera government (2010-2014) and the promotion of the "Pacific Schism"

\section{Wanderley dos Reis Nascimento Júnior*}

\begin{abstract}
RESUMO
O artigo analisa o papel do governo do presidente chileno Sebastián Piñera (2010-2014) na promoção da Aliança do Pacífico (AP). Visando compreender esta investida ao Pacífico, apresentamos uma análise comparada dos discursos de 21 de maio proferidos ao Congresso Nacional pelo mandatário e por sua antecessora Michelle Bachelet (2006-2010). Concluímos que o governo Piñera facilitou a criação de um bloco regional unido pelos ideários do livre mercado, indo na contramão dos demais modelos de integração na região.
\end{abstract}

Palavras-chave: Aliança do Pacífico; Sebastián Piñera; Direita.

\begin{abstract}
This article analyzes the role of the Chilean government of Sebastián Piñera (2010-2014) to promote Pacific Alliance (PA). Seeking to understand this investment to the Pacific, we present a comparative analysis of the speeches of May 21 delivered to Congress by the mandatary and his predecessor Michelle Bachelet (2006-2010). We conclude that the Piñera government facilitated the creation of a regional bloc united by the ideals of the free market, the grain of other integration models in the region.
\end{abstract}

Key-words: Pacific Alliance; Sebastián Piñera; Right.

\section{INTRODUÇÃo}

O objetivo deste trabalho é analisar o impulso dado pelo governo do presidente chileno Sebastián Piñera na promoção da Aliança do Pacífico. A ascensão da coalizão de direita "Alianza por Chile", encabeçada por Piñera, em 2010, apresentou a possibilidade de redirecionamento da política externa empreendida pelo país, sendo sob seu governo estabelecido a Aliança do Pacífico (AP), bloco regional que retoma os princípios do regionalismo aberto ${ }^{1}$.

\footnotetext{
* Bacharel em Relações Internacionais pela Pontifícia Universidade Católica de Goiás. Mestrando em Integração Contemporânea da América Latina pela Universidade Federal da Integração Latino-Americana. Bolsista do Programa Demanda Social/UNILA. Foz do Iguaçu/PR - Brasil.

1 Entendido como: "um processo de crescente interdependência no nível regional promovida por acordos preferenciais de integração e por outras políticas, num contexto de liberalização e desregulação capaz de fortalecer a competitividade dos países da região e, na medida do possível, constituir a formação de blocos para uma economia internacional mais aberta e transparente" (CEPAL, 1994 apud SOUZA, 2012, p. 113).

Conjuntura Global, vol. 4 n.3, set./dez., 2015, p. 333-350. 
Embora idealizada em 2010 na Cúpula Ibero-americana em Mar del Plata (Argentina), a AP surge oficialmente somente em 28 de abril de 2011 na I Cúpula da Aliança do Pacífico em Lima no Peru. O bloco que tem entre seus principais objetivos formar uma área de livre circulação de bens, serviços, capitais e pessoas é constituído por Chile, Colômbia, México e Peru.

Voltada diretamente para o aspecto econômico e comercial, a AP apresenta-se como uma iniciativa de retomada da influencia de Washington na região, portanto, em descompasso com as iniciativas regionalistas do início do século XXI no subcontinente que buscaram o regaste do papel do Estado na economia e um modelo de integração que não se atenha apenas a aspectos econômicos. Apresentada como um projeto ideológico, o bloco regional possui características como, por exemplo, o escasso relacionamento comercial entre os sócios, elemento que corrobora esta perspectiva. Assim como a confluência de diversos governos de direita na região do Pacífico latino-americano condiz com tal preposição.

Dessa forma, a guinada à direita ocorrida no país transandino, após duas gestões dos socialistas Ricardo Lagos (2000-2006) e Michelle Bachelet (2006-2010) que se inserem num período mais amplo de duas décadas de governos da coalizão de centroesquerda "Concertación de Partidos por la Democracia" (1990-2010), é um dos elementos a ser analisado neste novo contexto de regionalismo. Isto posto, faz-se necessário observar a trajetória de promoção da AP no Chile, a fim de averiguar se o governo de Piñera empreendeu um forte impulso em direção ao Pacífico em detrimento de um projeto de integração na região latino-americana como um todo.

Visando compreender esta investida ao Pacífico, empreendida pelo governo de Piñera, apresentamos uma análise comparada dos discursos de 21 de maio proferidos ao Congresso Nacional pelo mandatário e por sua antecessora Michelle Bachelet (20062010). Para isso, este trabalho está estruturado, além desta introdução e das considerações finais, em três seções: a seção debutante apresenta o contexto regional e as contradições inerentes ao processo de conformação da Aliança do Pacífico; a seção que segue apresenta as características da política externa chilena tendo em vista seu caráter de não ruptura com o regionalismo aberto como elemento norteador da orientação internacional do país, mas de um redirecionamento ao Pacífico; e, finalmente, apresentamos uma comparação entre os discursos de 21 de maio proferidos ao 
Congresso Nacional pelo governo Bachelet (2006-2010) que mantinha um rol latinoamericanista e o impulso dado por Piñera (2010-2014) na promoção da AP.

\section{A ALIANÇA DO PACÍFICO NO CONTEXTO REGIONAL LATINO-AMERICANO}

0 advento do século XXI apresentou para a América Latina um novo cenário para a integração regional, definida por Souza (2012) como "quarta onda de integração"2, impulsionada pelo cenário pós-Consenso de Washington ${ }^{3}$ e, consequentemente, pela ascensão de governos progressistas em diversos países da região4.

Neste sentido, esta "quarta onda" é definida por alguns teóricos como: regionalismo pós-liberal (SANAHUJA, 2009 e VEIGA; RIOS, 2007), pós-neoliberal (SERBIN, 2010) e regionalismo pós-hegemônico (RIGGIROZZI; TUSSIE, 2012), surgido com o esgotamento do regionalismo aberto - que primou na década de 90 pela abertura comercial - e pela apresentação de novas organizações regionais como a União de Nações Sul-americanas (UNASUL) e Comunidade de Estados Latino-americanos e Caribenhos (CELAC) que marcam o retorno do papel pragmático do Estado priorizando objetivos políticos e sociais.

Entretanto, neste contexto caracterizado por Sanahuja (2010, p. 90) pelo "esgotamento do regionalismo aberto como mecanismo de integração", eis que nos deparamos com uma realidade adversa, que instiga investigadores por sua complexidade: a criação em 28 de abril de 2011, em Lima (Peru), da AP que havia sido idealizada, em dezembro de 2010 na Cúpula Ibero-americana em Mar del Plata, pelos

2 A primeira onda compreende o período que se inicia com as independências dos países latinoamericanos e finda-se na grande crise mundial de 1914 a 1945; a segunda onda começa com as transformações regionais decorrentes da grande crise e conclui no fim dos anos 60 com o esgotamento do período expansivo do pós-guerra; e, a terceira cobre o período de declínio dessa onda larga de pós-guerra, no inicio dos anos 1970, até a chegada do século XXI (SOUZA, 2012).

3 Termo cunhado pelo economista estadunidense John Williamson, em 1990, para descrever o conjunto de propostas de reformas econômicas neoliberais que deveriam ser adotadas pelos países da América Latina como condição para renegociação das dívidas externas e acesso a recursos de agências financeiras. $O$ receituário resumia-se, basicamente, na recomendação de que o Estado se retirasse da economia (BANDEIRA, 2002).

4 Ver SILVA (2011).

Conjuntura Global, vol. 4 n.3, set./dez., 2015, p. 333-350. 
presidentes Alan García (Peru), Sebastián Piñera (Chile), Felipe Calderón (México) e Juan Manuel Santos (Colômbia) com ênfase no livre comércio (DADE; MEACHAM, 2013).

A complexidade em questão refere-se ao fato de que o surgimento da AP, caracterizado por Fiori (2013) como "cisma do Pacífico" ${ }^{5}$, de certa forma, “[...] reavivou o debate sobre diferentes tipos de cooperação e grupos regionais, pois retomou o modelo de regionalismo aberto na América Latina"6 (NOLTE; WEHNER, 2013, p. 3, tradução nossa). Portanto, o surgimento da AP revive na região o modelo de regionalismo que mantém a lógica da integração dos anos 90 de liberalização comercial, indo de encontro aos novos projetos que surgem na América Latina que buscam consensos políticos a fim de priorizar a integração não apenas econômica, mas política e social que abranjam aspectos como, por exemplo, energia, infraestrutura e segurança nacional.

Este novo contexto do regionalismo latino-americano apresenta-se como um mosaico e neste cenário múltiplo de diversos grupos regionais não existe homogeneidade havendo, portanto, "vários eixos de integração regional com modelos econômicos marcadamente distintos"7 (BRICEÑO RUIZ, 2013, p. 13, tradução nossa). Dessa forma, Briceño Ruiz (2013) indica a existência de três eixos de integração: o eixo da integração aberta dos Tratados de Livre Comércio (TLC) e da AP; o eixo revisionista do Mercado Comum do Sul (MERCOSUL); e o eixo anti-sistêmico da Aliança Bolivariana para os Povos da Nossa América (ALBA).

À vista disso, a América Latina compreende um amplo grupo de blocos que priorizam questões diferentes e refletem diferentes tipos de integração caracterizando o que Gardini (2013, n.p., tradução nossa) apresenta como "regionalismo modular" uma vez que, "a escolha e adesão de projetos de integração regional, por parte dos Estados, refletem seus interesses nacionais e prioridades da política externa em áreas específicas"8. Sendo assim, cada país pode escolher, de acordo com seus interesses, como atuar em âmbito regional integrando-se com Estados que compartilham opiniões

50 termo refere-se à Aliança do Pać́fico, pois a constituição desse bloco regional representou o aparecimento de um novo eixo político-diplomático e econômico dentro do continente que retoma os preceitos do regionalismo aberto e destoa-se, portanto, de outras iniciativas integracionistas como o MERCOSUL e a UNASUL que buscaram o regaste do papel do Estado na economia e um modelo de integração que não se atenha apenas a aspectos econômicos (FIORI, 2013).

6 "The PA has revived the debate on these different types of regional cooperation and groupings because it has returned the open regionalism model to Latin America".

7 "varios ejes de integración regional con modelos económicos marcadamente distintos".

8 "[...] states pick and choose membership of regional integration projects reflecting their national interests and foreign policy priorities in specific areas [...]".

Conjuntura Global, vol. 4 n.3, set./dez., 2015, p. 333-350. 
afins. A AP é um claro exemplo desta característica de que blocos de integração regional estão suscetíveis às ideologias e vontade política dos governos em questão.

Portanto, mesmo que os membros da AP defendam seu caráter apolítico, tornase evidente o caráter ideológico e seu alinhamento com Washington por algumas razões: o fato de os quatro países que formam a AP, antes de formarem o bloco já possuíam TLCs com os Estados Unidos da América (EUA) e com muitos países asiáticos; a estreita relação econômica entre México e EUA, uma vez que o país faz parte do Tratado NorteAmericano de Livre Comércio (NAFTA); e, por último, mas não menos importante, o fato dos países que constituem o bloco apresentarem um escasso relacionamento comercial entre si (FIORI, 2013). Neste sentido, cabe ressaltar aqui o escasso relacionamento comercial entre os membros da AP (Gráfico 1), uma vez que os principais sócios comerciais destes países são os EUA e a China. Estes dados são importantes, pois demonstram que não se sustenta o argumento de constituição do bloco regional como instrumento que visa potencializar o já existente intercâmbio comercial entre os países membros em detrimento do resto do mundo.

Gráfico 1: Cotas de exportação para os países da AP segundo destino (2013)

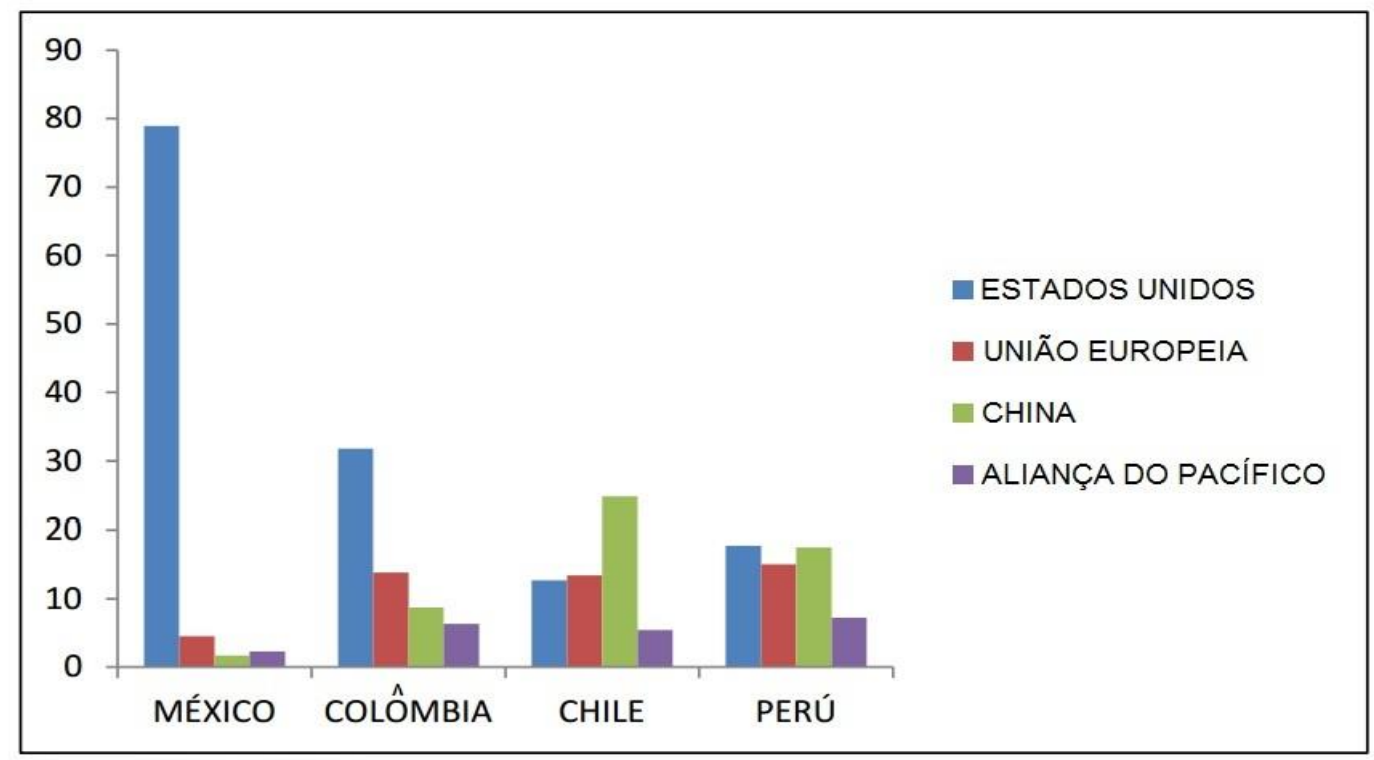

Fonte: Blanco Estévez (2015, p. 5, tradução nossa). 
Sem nos determos em uma análise exaustiva destes dados e suas implicações9, percebe-se que as exportações intrabloco são escassas em comparação com outros parceiros comercias como China e EUA. Considerando especificamente o caso chileno, as exportações para os países do bloco representam apenas 5,4\% do total de suas exportações no ano de 2013. Neste sentido, também nos apresenta Blanco Estévez (2015, p. 9, tradução nossa) que "a intensidade e profundidade das relações de investimento direto entre os países latino-americanos refletem, assim como as relações comerciais, uma escassa integração econômica na AP"10.

Para o Chile, por exemplo, a China é seu principal sócio comercial e apesar de suas exportações para a AP terem representado 4 bilhões 153 milhões de dólares estadunidenses em 2013, o valor total de suas exportações para o MERCOSUL, por exemplo, representaram, no mesmo ano, 6 bilhões 683 milhões de dólares (Quadro 1), ou seja, o relacionamento comercial do país se dá de maneira mais intensa com países deste último.

Quadro 1: Matriz de exportações de bens entre os membros da Aliança do Pacífico e do MERCOSUL, 2014. (em bilhões de dólares)

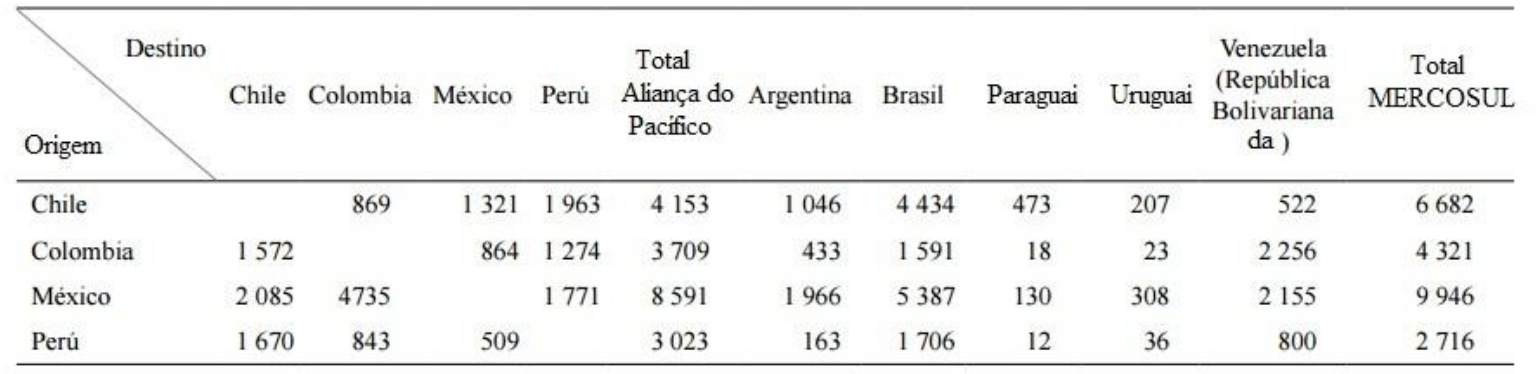

$[\cdots]$

Fonte: CEPAL (2014, p. 41, tradução nossa).

Isto posto, percebe-se que conforme bem apresenta Fiori (2013),

[...] o 'cisma do Pacífico' tem mais importância ideológica do que econômica, porque sua força política decorre inteiramente da sua aliança com os EUA. Na verdade, os três países sul-americanos associados à 'Aliança do Pacífico' fazem parte do processo de criação da Trans-Pacific Economic Partnership (TPP), que se transformou na peça central da política externa comercial da administração Obama e de seu projeto de afirmação do poder econômico e militar norteamericano na região do Pacífico. (FIORI, 2013, p. 38).

9 Ver BLANCO ESTÉVEZ (2015).

10 "Ia intensidad y profundidad de las relaciones de inversión directa exterior entre los países latinoamericanos reflejan, al igual que las relaciones comerciales, una escasa integración económica en la AP".

Conjuntura Global, vol. 4 n.3, set./dez., 2015, p. 333-350. 
Assim, estes fatos indicam para o que pode caracterizar-se como tentativa de restauração da Área de Livre Comércio das Américas (ALCA) que fora enterrada na Cúpula das Américas de Mar del Plata em 2005, e de (res)surgimento do regionalismo aberto na região, que como veremos na seção seguinte, nunca desapareceu por completo, estando presente atualmente como eixo norteador da política externa chilena.

\section{REDIRECIONAMENTO SEM RUPTURA: A POLÍTICA EXTERNA CHILENA}

A volta da direita ao poder, no Chile, com o triunfo, em 2010, do candidato Sebastián Piñera da coalizão de direita "Alianza por Chile" - que agrupa a Renovação Nacional (RN) e a União Democrática Independiente (UDI), após duas décadas de governos da coalizão de centro-esquerda "Concertación de Partidos por la Democracia" (1990-2010) -, é, também, um dos fatores importantes a ser considerado ao analisarmos o caráter ideológico da AP, já que o país é um dos fundadores do bloco.

Entendendo que a política exterior é fixada, no caso chileno, a exemplo do caso brasileiro, pela presidência da república e é caracterizada por ser uma política pública de primeira ordem (GUMUCIO, 2004), pode-se compreender, segundo Kingdon (1995, apud DOCKENDORFF; LOPEZ, 2014, p. 145, tradução nossa), "que uma mudança de governo pode abrir uma 'janela política' para que novos temas adquiram prominência e sejam considerados pelos tomadores de decisão"11, fato que possibilita corroborar a ideia de que o governo Piñera tenha dado um forte impulso na consolidação da Aliança do Pacífico após sua chegada ao poder central chileno.

Esta guinada à direita foi apresentada, ainda em 2010, por Borón, como um anúncio da possibilidade de retomada da influência estadunidense na região e da redução do protagonismo de um projeto de emancipação latino-americano. Assim, Borón (2010, n.p., tradução nossa) apresenta que:

[...] com o triunfo de Piñera o bloco direitista controla, com a honrosa exceção do Equador, todo o flanco do Pacífico latino-americano [...] a belicosa contraofensiva imperial dos Estados Unidos (Quarta Frota, bases militares na Colômbia, golpe em Honduras, reconhecimento das fraudulentas eleições neste país, etc.) contará a partir de março com um novo aliado, livre de qualquer

11 "que un cambio de gobierno puede abrir una 'ventana política' para que nuevos temas adquieran prominencia y sean considerados por los tomadores de decisión".

Conjuntura Global, vol. 4 n.3, set./dez., 2015, p. 333-350. 
compromisso, ainda que seja retórico, com o projeto emancipador latinoamericano ${ }^{12}$.

Percebe-se que a eleição de Piñera fortaleceria a confluência ideológica na região do Pacífico latino-americano e isto possibilitaria um processo, após a fracassada tentativa da ALCA, de retomada de influência estadunidense na região. Isto posto, cabe ressaltar que o regionalismo aberto esteve presente como eixo teórico de orientação da política externa chilena em todos os governos da Concertación ainda que, a depender da vontade política, sua orientação oscilava entre uma inserção global através dos TLCs ou para a promoção de um processo de integração latino-americana. Logo,

[...] a ênfase de estar mais ativamente no mundo e de tirar vantagens do cenário globalizante aberto no Pós-Guerra Fria teve muito mais força que a proclamada prioridade política de impulsionar o processo de integração sul-americana (ou da América Latina) que exigia grande vontade política e perseverança para lograr entendimentos efetivos com outros governos vizinhos ${ }^{13}$. (MAIRA, 2010, p. 85, tradução nossa).

Exemplos desta oscilação de vontade política podem ser percebidos, por um lado, com a assinatura por parte do presidente chileno Ricardo Lagos de TLCs com EUA, União Europeia, China, Coreia do Sul e Japão ou, por outro lado, com a criação do Conselho de Defesa Sulamericano, em 2008, que se deu no primeiro governo Michelle Bachelet em sua Presidência Pro Tempore da UNASUL corroborando que "os incentivos para impulsionar a integração sul-americana durante o governo da presidenta Michelle Bachelet, fora especialmente poderosos"14 (MAIRA. 2010, p. 86, tradução nossa).

Dessa forma, mesmo existindo uma continuidade na política externa chilena com relação aos 20 anos de governo da Concertación, no que se refere à defesa do regionalismo aberto, possibilitando ao país tanto uma inserção internacional através da liberalização comercial quanto de um projeto de integração regional, o início do governo

12 "con el triunfo de Piñera el bloque derechista controla, con la honrosa excepción del Ecuador, todo el flanco del Pacifico latino-americano [...] la belicista contraofensiva imperial de Estados Unidos (Cuarta Flota, bases militares en Colombia, golpe en Honduras, reconocimiento de las fraudulentas elecciones de ese país, etcétera) contará a partir de marzo con un nuevo aliado, liberado de cualquier compromiso, aunque sea retórico, con el proyecto emancipatorio latinoamericano".

13 "el énfasis de estar más activamente en el mundo y de sacar ventajas del escenario globalizador abierto en la Pos-Guerra Fría tuvo mucho más fuerza que la proclamada prioridad política de impulsar el proceso de integración sudamericana (o de América Latina) que exigía gran voluntad política y perseverancia para lograr entendimentos efectivos con otros gobiernos vecinos".

14 "los incentivos para impulsar la integración sudamericana durante el gobierno de la presidenta Michelle Bachelet, fueron especialmente poderosos".

Conjuntura Global, vol. 4 n.3, set./dez., 2015, p. 333-350. 
de Sebastián Piñera parece ter impulsionado a adesão do Chile à AP e, de certa forma, representado a volta de uma tendência "isolacionista" conforme bem indicava Borón (2010, n.p., tradução nossa):

\footnotetext{
Na Cúpula de Mar del Plata que culminou com o naufrágio da ALCA as vozes cantantes a favor deste acordo foram as de Ricardo Lagos e Vicente Fox, sob o olhar complacente de George W. Bush. Agora essa tendência 'isolacionista' - e, no fundo, anti-latino-americanista - se acentuará ainda mais, revertendo uma profunda vocação latino-americana que o Chile soube ter e que sob a presidência de Salvador Allende chegou ao seu apogeu ${ }^{15}$.
}

Portanto, percebe-se que em 2010, com a chegada da coalizão de direita ao poder central no Chile, Borón (2010) já indicava para uma tendência anti-latinoamericana uma vez que os setores conservadores no país já tendiam para um caráter anti-regional guiados pela potência do norte.

\section{BACHELET E PIÑERA: DO LATINOAMERICANISMO AO “CISMA DO PACÍFICO”}

Partindo do pressuposto de que a Análise do Discurso é uma ferramenta que está presente nas teorias das Relações Internacionais desde a década de 1980 e de que “as mensagens a nação são eminentemente políticas; se caracterizam por ser tanto uma instância de manifestação e legitimação das ideologias partidárias e - reciprocamente - o lugar de conformação da mesma e do grupo que a subscreve"16 (VAN DIJK 1996, apud LOPÉZ ESCARCENA 2013, p. 127, tradução nossa), apresentaremos uma análise comparada dos discursos presidenciais anuais de 21 de maio perante o Congresso Nacional nos governos Bachelet (2006-2010) e Piñera (2010-2014), a fim de demonstrar a partir desta comunicação oficial o impulso do governo direitista em direção ao Pacífico.

Neste sentido, a análise comparada dos discursos nos permitirá compreender, sem nos determos a uma análise estritamente semântica, as opções de inserção internacional definidas por ambos os governos, uma vez que os discursos representam o

15 "En la Cumbre de Mar del Plata que culminó con el naufragio del ALCA las voces cantantes a favor de ese acuerdo fueron las de Ricardo Lagos y Vicente Fox, bajo la complacida mirada de George W. Bush. Ahora esa tendencia 'aislacionista' -y, en el fondo, antilatinoamericana- se acentuará aún más, revirtiendo una profunda vocación latinoamericana que Chile supo tener y que bajo la presidencia de Salvador Allende llegó a su apogeo". 16 "Ios mensajes a la nación son eminentemente políticos; se caracterizan por ser tanto una instancia de manifestación y legitimación de las ideologías partidarias y - reciprocamente - el lugar de conformación de la misma y del grupo que la suscribe".

Conjuntura Global, vol. 4 n.3, set./dez., 2015, p. 333-350. 
choque da língua com a ideologia. No contexto chileno, o discurso de 21 de maio perante o Congresso pode servir de guia para indicar os rumos que tomaram a política externa de determinado governo, pois segundo Lopéz Escarcena (2013, p. 126, tradução nossa):

\begin{abstract}
Esses discursos [de 21 de maio] à nação não são somente uma prestação de contas: também constituem um meio que os mandatários utilizam para (re)ativar o apoio da cidadania. A mensagem presidencial se converte em um ato estratégico de comunicação por parte dos Chefes de Estado. Para gerir esse apoio, apresentam uma visão de país para o futuro e uma cosmovisão partidária, sustentada em valores que dão sentido e transcendência; promovem sua imagem como mandatário; e destacam as ações realizadas e a necessidade de empreender aquelas que ainda não foram colocadas em pratica ${ }^{17}$.
\end{abstract}

De maneira sucinta, pode-se perceber nos discursos de 21 de maio da presidenta Bachelet que a América Latina obteve especial atenção nas ações do seu governo, uma vez que, em 2007, a mandatária apresenta claramente que: "a primeira prioridade da política externa de [seu] governo é a integração na região, levando adiante projetos viáveis e concretos"18 (BACHELET, 2007, p. 41, tradução nossa); no ano seguinte, menciona que: "temos um desafio importante em nossa região. Quanto mais ampla e sólida a integração na América Latina, melhor escutará nossa voz no mundo"19 (BACHELET, 2008, p. 17, tradução nossa); e finalmente, em 2009, ao reafirmar que: "a política prioritária para América Latina e Caribe rendeu frutos e hoje Chile está mais perto de seus vizinhos e amigos latino-americanos"20 (BACHELET, 2009, p. 21, tradução nossa).

Entretanto, ao considerarmos tais discursos, torna-se claro, também, o crescimento da prioridade dada ao "eixo Pacífico" que aparece, inicialmente, no discurso de 2007, ainda que a integração proposta com o eixo Pacífico tenha sido pensada, pela presidenta, como "ponte" para conectar as duas regiões, dessa forma Bachelet afirma: "podemos como país, servir de poderoso vínculo entre América Latina e o mundo, e

17 "Estos discursos [del 21 de mayo] a la nación no son solamente una rendición de cuentas: también constituyen un medio que los mandatarios emplean para (re)activar el apoyo de la ciudadanía. El mensaje presidencial se convierte en un acto estratégico de comunicación de parte de los Jefes de Estado. Para gestionar ese apoyo, plasman una mirada de país para el futuro y una cosmovisión partidaria, sostenida en valores que le dan sentido y trascendencia; promueven la imagen de su cabeza visible, el mandatario; y destacan las acciones realizadas y la necesidad de emprender aquéllas que aún no se han llevado a la práctica".

18 "la primera prioridad de la política exterior de [su] gobierno es la integración en la región, llevando adelante proyectos viables y concretos".

19 "tenemos un desafío importante en nuestra región. Mientras más amplia y sólida es la integración en América Latina, mejor se hará escuchar nuestra voz en el mundo".

20 "Ia política prioritaria hacia América Latina y El Caribe ha rendido sus frutos y hoy Chile está más cerca de sus vecinos y amigos latinoamericanos".

Conjuntura Global, vol. 4 n.3, set./dez., 2015, p. 333-350. 
especialmente com a Ásia Pacífico. E o faremos sempre neste aspecto com visão de país"21 (BACHELET, 2007, p. 41, tradução nossa). Não indicando, portanto, uma inserção rumo ao Pacífico que menospreze vizinhos como Argentina e Brasil.

E, posteriormente, em 2008 reafirma que:

[...] com maior integração na região, outro importante desafio que temos é aumentar os laços com a Ásia e o Pacífico, região que pode ser considerada a nova fronteira da América Latina, e certamente, uma região com a qual quase tudo está por fazer ${ }^{22}$ (BACHELET, 2008, p. 18, tradução nossa).

Para o governo Bachelet, a integração com os países do Pacífico se daria no sentido de que o país seria um elo de vinculação com a América Latina, não de forma unilateral. Isto é evidenciado em seu último discurso perante o Congresso, em 2009, ao afirmar que: "estamos terminando de construir o Corredor Interamericano Central de quatro mil 700 quilômetros que unirá o Atlântico com o Pacífico entre Brasil, Bolívia e Chile"23 (BACHELET, 2009, tradução nossa), pois considera o Brasil como país importante em sua estratégia de vinculação com o Pacífico.

Esta orientação ao Pacífico evidenciada no último governo da Concertación é vista como um erro de estratégia por Maira (2012, p. 9, tradução nossa) ao apresentar que está convencido de que:

0 grande erro da estratégia internacional chilena, que não é privativa do governo de Piñera, desafortunadamente havia começado um pouco antes, no último governo da Concertación em sua primeira etapa, é a ideia de um 'Eixo do Pacífico', porque isto não tem nada a ver com o interesse nacional chileno. 0 verdadeiro interesse nacional chileno reside na integração da América do Sul, e é o entendimento preferente entre nossos países, e em especial com os grandes países do Atlântico, que são os que poder ter um comércio incrementado com a região da Ásia e do Pacífico ${ }^{24}$.

21 "podemos como país, servir de poderoso vínculo entre América Latina y el mundo, y muy especialmente con el Asia Pacífico. Y lo haremos siempre en esta materia con visión de país".

22 "con mayor integración en la región, otro importante desafío que tenemos es acrecentar los lazos con el Asia Pacífico, región que puede ser considerada la nueva frontera de América Latina, y por cierto, una región con la cual casi todo está por hacerse".

23 "estamos terminando de construir el Corredor Interoceánico Central de cuatro mil 700 kilómetros que unirá el Atlántico con el Pacífico entre Brasil, Bolivia y Chile".

24 "el gran error de la estratégia internacional chilena, que no es privativa del gobierno de Piñera, por desgracia había empezado un poco antes, en el último gobierno de la Concertación en su primera etapa, es la idea de un 'Eje del Pacífico', porque eso no tiene nada que ver con el interés nacional chileno. El verdadero interés nacional chileno reside en la integración de América del Sur, y es el entendimiento preferente entre nuestros países, y en especial con los grandes países del Atlántico, que son los que pueden tener un comercio incrementado con la región del Asia del Pacífico".

Conjuntura Global, vol. 4 n.3, set./dez., 2015, p. 333-350. 
Logo, a ideia de um "eixo do Pacífico", apesar de ter surgido inicialmente no governo Bachelet como tema para o qual a agenda de política externa daria especial atenção, fora intensificada pelo governo Piñera, ainda que, a priori, o caráter latinoamericanista do seu governo tenha surpreendido até os mais críticos. Assim, em seu primeiro discurso diante do Congresso, o presidente afirmou que:

Durante nosso governo vamos aprofundar a relação com a América Latina, especialmente com nossos países vizinhos, sem que isto implique na renúncia ao nosso exitoso modelo de desenvolvimento exportador a outras latitudes ${ }^{25}$ (PIÑERA, 2010, p. 41, tradução nossa).

Percebe-se, inicialmente, a disposição de buscar incrementar os vínculos com os países vizinhos, fato que foi demonstrado apenas em seu primeiro e segundo discurso quando afirma que se aprofundará "laços de integração com a América Latina, assumindo nosso papel na Unasul e Mercosul e fortalecendo a Aliança do Pacífico, recentemente acordada entre Chile, México, Colômbia e Peru"26. (PIÑERA, 2011, p. 26, negrito do autor, tradução nossa).

Por outro lado, ainda em 2010, o presidente inicia uma série de viagens pela Ásia fato que está em consonância com seu discurso já que o governo seguiria:

[...] desenvolvendo [seus] vínculos com a União Europeia, o Nafta, que agrupa Estados Unidos, Canadá e México, e Ásia-Pacífico, através do Trans-Pacific Partnership (TPP), que incluirá países de ambas as bordas do Oceano Pacífico e deverá constituir-se na maior e auspiciosa zona de livre comércio do mundo ${ }^{27}$ (PIÑERA, 2011, p. 26, tradução nossa).

Constata-se aqui o interesse do governo Piñera na promoção do TPP que tornou-se peça fundamental da política externa estadunidense na afirmação de seu poderio na região do Pacífico. Dessa forma, a exemplo dos discursos anteriores, em seu último pronunciamento como presidente da República perante o Congresso, Piñera afirma que continua,

25 "Durante nuestro gobierno vamos a profundizar la relación con América Latina, especialmente con nuestros países vecinos, sin que ello implique la renuncia a nuestro exitoso modelo de desarrollo exportador hacia otras latitudes".

26 "lazos de integración con América Latina, asumiendo nuestro rol en Unasur y Mercosur y fortaleciendo la Alianza del Pacífico, recientemente acordada entre Chile, México, Colombia y Perú".

27 "desarrollando [sus] vínculos con la Unión Europea, el Nafta, que agrupa a Estados Unidos, Canadá y México, y el Asia-Pacífico, através del Trans-Pacific Partnership (TPP), que incluirá países de ambos bordes del Océano Pacífico y deberá constituirse en la zona de libre comercio más grande y auspiciosa del mundo".

Conjuntura Global, vol. 4 n.3, set./dez., 2015, p. 333-350. 
[...] avançando as negociações do Trans-Pacific Partnership (TPP), o processo de integração mais audaz entre as principais economias de ambos os lados do Pacífico, que busca criar a maior área de livre comércio do mundo. A isto se soma a Aliança do Pacífico, da qual o Chile, juntamente com Colômbia, México e Peru, é país fundador028. (PIÑERA, 2013, p. 7, tradução nossa).

Avança-se os vínculos com o Pacífico enquanto o papel chileno no processo de integração latino-americana como um todo é renegado a segundo plano, centrado em compromissos previamente assumidos como a Presidência Pro Tempore da CELAC. Isto pode ser evidenciado pelo fato de não haver, nos discursos de 2012 e 2013, nenhuma menção ao papel, antes considerado principal pelo governo de sua antecessora, da integração da América Latina como eixo fundamental na política externa chilena.

Outro fator importante que podemos nos referir como indicador da vontade política por parte dos presidentes na criação da AP é a frequência com que foram desenvolvidos os encontros, tendo sido realizadas oito cúpulas presidenciais, no período do governo Piñera, três somente em 2012 (BRIONES; DOCKENDORFF, 2015). Em contrapartida, percebe-se que o mesmo engajamento dos países da AP não se dá, por exemplo, com a UNASUL, pois:

Seu objetivo principal [da AP] é corroer o bloco de países sul-americanos e especificamente a Unasul. Isto acabamos de ver na reunião de Cochabamba, pois não participou nenhum dos presidentes dos três países da Aliança (Colômbia, Peru e Chile, que são membros, juntamente com Costa Rica e México) ${ }^{29}$ (BORÓN, 2013).

O não comparecimento dos presidentes dos países sul-americanos membros da AP à Cúpula Presidencial da UNASUL em Cochabamba sinaliza um distanciamento, por parte do bloco, das iniciativas regionais empreendidas por Brasília, Buenos Aires e Caracas. Desta forma, Chile, Colômbia e Peru - por estarem ideologicamente alinhados se distanciam dos projetos regionais fomentados sob a liderança brasileira, como é o

28 "avanzando en las negociaciones del Trans-Pacific Partnership (TPP), el proceso de integración más audaz entre las principales economías de ambos lados del Pacífico, que busca crear el área de libre comercio más grande del mundo. A esto se suma la Alianza del Pacífico, de la cual Chile, junto con Colombia, México y Perú, es país fundador".

29 "Su objetivo principal [de la AP] es erosionar el bloque de países suramericanos y especificamente la Unasur. Eso lo acabamos de ver en la reunión de Cochabamba, pues no participó ninguno de los presidentes de los tres países de la Alianza (Colombia, Perú y Chile, que son miembros, junto a Costa Rica y México)".

Conjuntura Global, vol. 4 n.3, set./dez., 2015, p. 333-350. 
caso da UNASUL, e tratam de auxiliar o México na sua tentativa de aproximação comercial e política com a América do Sul.

Assim, Borón (2010 e 2013) explicita o caráter ideológico da AP e, por consequência, o papel do governo Piñera na promoção do "cisma do Pacífico" que tendeu mais à promoção desta iniciativa pela confluência ideológica com os demais países - Colômbia, México e Peru - em detrimento dos projetos já em voga no subcontinente. Isto posto, o próprio Piñera reconhece em uma entrevista ao periódico El Tiempo (2012, n.p., tradução nossa) que:

\footnotetext{
Na região existem visões e modelos distintos. 0 modelo e desenvolvimento que seguem países como Cuba, Venezuela e Bolívia é muito diferente da visão de como enfrentar o desenvolvimento político e econômico que seguimos países como México, Colômbia, Peru, Chile e Uruguai. Mas temos que aprender a conviver dentro da diversidade ${ }^{30}$.
}

A fala do presidente chileno sinaliza um bloco ideológico antagônico a outros projetos de integração, por apresentarem modelos de desenvolvimentos distintos, indicando uma superação do caráter comercial da AP adquirindo componente político. Algo que com a eleição de Bachelet (2014-2017) para um novo mandato, segundo informações de seu chanceler31, será combatido.

\section{CONSIDERAÇõES FINAIS}

Percebemos que a AP surge no contexto de regionalismo pós-neoliberal, entretanto retoma os preceitos de liberalização comercial do regionalismo aberto, apresentando características ideológicas por sua estreita proximidade com Washington e, principalmente, pelo escasso relacionamento comercial entre os membros do bloco. Neste sentido, visualizamos que o surgimento do bloco, em 2011, representa uma cisma na região, pois demarca o aparecimento de um novo eixo político-diplomático e econômico dentro do continente que se destoa de outras iniciativas integracionistas

30 "En la región hay visiones y modelos distintos. El modelo de democracia y desarrollo que siguen países como Cuba, Venezuela y Bolivia es muy distinto a la visión de cómo enfrentar el desarrollo político y económico que seguimos países como México, Colombia, Perú, Chile y Uruguay. Pero tenemos que aprender a convivir dentro de la diversidad".

31 Ver http://www.latercera.com/noticia/politica/2014/03/674-569424-9-canciller-munoz-proponeconvergencia-entre-mercosur-y-alianza-del-pacifico.shtml

Conjuntura Global, vol. 4 n.3, set./dez., 2015, p. 333-350. 
como o MERCOSUL e a UNASUL, que buscaram o regaste do papel do Estado na economia e um modelo de integração que não se atenha apenas a aspectos econômicos.

Constatamos que a chegada de Piñera ao poder central no Chile, em 2010, apesar de não apresentar uma ruptura com os ideários da política externa do país caracterizada desde a redemocratização pelo regionalismo aberto - demonstrou um redirecionamento para o Pacífico, iniciado no final do primeiro governo Bachelet, mas intensificado com a chegada da direita ao poder no país.

Finalmente, através da análise comparada dos discursos percebemos que se, por um lado, o governo Bachelet (2006-2010) apresentou a integração da América Latina como eixo fundamental da política externa chilena, por outro lado, a administração do presidente Piñera (2010-2014) demonstrou seu caráter anti-latino-americanista, característico dos setores conservadores chilenos, pois, mesmo mantendo um discurso latino-americanista em seu primeiro ano de mandato, este impulso inicial em direção à integração de Nuestra América viu-se cada vez mais reduzido com a intensificação das relações com a região do Pacífico em detrimento das relações com seus vizinhos sulamericanos. Concluímos que a ascensão de um governo de direita facilitou a criação de um bloco regional unido pelos ideários do livre mercado, indo na contramão dos modelos de integração do período definido como regionalismo pós-neoliberal.

\section{REFERÊNCIAS}

BACHELET, Michelle. (2009). Mensaje presidencial del 21 de mayo de 2009. Valparaíso: Mensaje al país de la Presidenta de la República, Michelle Bachelet Jeria. Disponível em: [http://www.camara.cl/camara/media/docs/discursos/21mayo_2009.pdf] Acesso em: 12 jun. 2015.

(2008). Mensaje presidencial del 21 de mayo de 2008. Valparaíso: Mensaje al país de la Presidenta de la República, Michelle Bachelet Jeria. Disponível em: [http://www.camara.cl/camara/media/docs/discursos/21mayo_2008.pdf] Acesso em: 12 jun. 2015.

(2007). Mensaje presidencial del 21 de mayo de 2007. Valparaíso: Mensaje al país de la

Presidenta de la República, Michelle Bachelet Jeria. Disponível em: [http://www.camara.cl/camara/media/docs/discursos/21mayo_2007.pdf] Acesso em: 12 jun. 2015.

. (2006). Mensaje presidencial del 21 de mayo de 2006. Valparaíso: Mensaje al país de la Presidenta de la República, Michelle Bachelet Jeria. Disponível em: [http://www.camara.cl/camara/media/docs/discursos/21mayo_2006.pdf] Acesso em: 12 jun. 2015. 
BANDEIRA, Luiz Alberto Moniz. (2002). As políticas neoliberais e a crise na América do Sul. Rev. bras. polít. Int., Brasília, v. 45, n. 2, p. 135-146. Disponível em: <http://www.scielo.br/scielo.php?script=sci_arttext\&pid=S0034-

$73292002000200007 \& \operatorname{lng}=e n \& n r m=i s o>$. Acesso em: 09 jan. 2016.

BLANCO ESTÉVEZ, Adrián. (2015). LA ALIANZA DEL PACÍFICO: Un largo camino por recorrer hacia la integración. In: Latin American Program. Washington: Wilson Center. Disponível em: [http://www.wilsoncenter.org/sites/default/files/La_Alianza_del_Pacifico_Blanco_0.pdf] Acesso em: 12 jun. 2015.

BORÓN, Atilio. (2013). Estados Unidos y la Alianza del Pacífico sabotearon la reunión de Cochabamba, 8 julho 2013. Disponível em: [www.aporrea.org/tiburon/n232279.html] Acesso em: 24 maio 2015.

- (2010). Elecciones en Chile: el original y la copia. América Latina en Movimiento [online]. Quito: ALAI, 22 jan. 2010 . Disponível em: [http://www.alainet.org/es/active/35674] Acesso 24 maio 2015.

BRICEÑO RUIZ, José. (2013) Ejes y modelos en la etapa actual de la integración económica regional en América Latina. In: Estudios Internacionales 175. Santiago: Instituto de Estudios Internacionales, Universidad de Chile.

BRIONES, Sebastián; DOCKENDORFF, Andrés. (2015). Continuidad y cambio en la política exterior chilena en el gobierno de Sebastián Piñera (2010-2014). Santiago: Instituto de Estudios Internacionales. Disponível em: [http://www.scielo.cl/pdf/rei/v47n180/art06.pdf] Acesso em: 22 maio 2015.

CEPAL. (2014). La Alianza del Pacífico y el MERCOSUR: Hacia la convergencia en la diversidad. Santiago: CEPAL. Disponível em: [http://repositorio.cepal.org/bitstream/handle/11362/37304/S1420838_es.pdf] Acesso em: 20 jun. 2015.

DADE, Carlo; MEACHAM, Carl. (2013). The Pacific Alliance: An Example of Lessons Learned. Washington: CSIS. Disponível em: [http://csis.org/files/publication/130711_CDadeCMeacham_PacificAlliance.pdf]. Acesso em: 15 maio 2015.

DOCKENDORFF, Andrés; LOPEZ, Miguel A. (2014). La irrupción de la Alianza del Pacifico: ¿Cambio en la agenda de la política exterior chilena?. Revista de Relaciones Internacionales, № 47. La Plata: UNLP, № 45. Disponível em: [http://revistas.unlp.edu.ar/RRIIIRI/article/view/810] Acesso em: 15 maio 2015.

El Tiempo. (2012). 'La OEA tiene que mejorar': Presidente de Chile Sebastián Piñera habló con EL TIEMPO sobre la Alianza del Pacífico y la integración regional, 16 Junho, 2012. Disponível em: [http://www.eltiempo.com/archivo/documento/CMS-11953401] Acesso em: 22 maio 2015.

FIORI, José Luís. (2013). O Brasil e seu "entorno estratégico" na primeira década do século XXI. In: SADER, Emir (Org.). 2013. 10 anos de governos pós-neoliberais no Brasil: Lula e Dilma. Rio de Janeiro: Bomtempo. p. 31-52.

GUMUCIO, Cristián Parker. (2004). Sobre política exterior iniciando el siglo XXI. In: Revista de Sociologia, № 18. Santiago: FCS, Universidad de Chile, 2004, p 149-157. Disponível em: 
[http://www.facso.uchile.cl/publicaciones/sociologia/articulos/18/1808-ParkerGumucio.pdf] Acesso em: 19 jun. 2015.

LOPÉZ ESCARCENA, Ignacio. (2013). Análisis del primer mensaje a la nación de los Presidentes Lagos y Piñera.In: Cuadernos.info. Santiago: [online], № 32, p.125-134. Disponível em: [http://www.scielo.cl/scielo.php?pid=S0719-367X2013000100012\&script=sci_arttext] Acesso em 24 maio 2015.

MAIRA, Luis. (2012). América Latina y la política exterior chilena. Santiago: Fundação FriedrichEbert. Disponível em: [http://library.fes.de/pdf-files/bueros/chile/08810-20120127.pdf] Acesso em: 22 jun. 2015.

- (2010). La Política Exterior de los Gobiernos de la Concertación: Contexto, Raíces, Formulación Logros y Restricciones. In: QUIROGA, Yesko; ENSIGNIA, Jaime (editores). Chile en la Concertación [1990-2010] Una mirada crítica, balance y perspectiva. Santiago: Friedrich Ebert Stiftung, Volume 2.

NOLTE, Detlef; WEHNER, Leslie. (2013). The Pacific Alliance Casts Its Cloud over Latin America.Hamburgo: German Institute of Global and Area Studies. Disponível em: [http://www.giga-hamburg.de/de/system/files/publications/gf_international_1308.pdf] Acesso em: 22 maio 2015.

PIÑERA, Sebastián. (2013). Mensaje presidencial del 21 de mayo de 2013. Valparaíso: Mensaje al país del Presidente de la República, Sebastián Piñera Echenique. Disponível em: [http://www.camara.cl/camara/media/docs/discursos/21mayo_2013.pdf] Acesso em: 22 maio 2015.

(2012). Mensaje presidencial del 21 de mayo de 2012. Valparaíso: Mensaje al país del Presidente de la República, Sebastián Piñera Echenique. Disponível em: [http://www.camara.cl/camara/media/docs/discursos/21mayo_2012.pdf] Acesso: 22 maio 2015.

(2011). Mensaje presidencial del 21 de mayo de 2011. Valparaíso: Mensaje al país del Presidente de la República, Sebastián Piñera Echenique. Disponível em: [http://www.camara.cl/camara/media/docs/discursos/21mayo_2011.pdf] Acesso em: 22 maio de 2015.

(2010). Mensaje presidencial del 21 de mayo de 2010. Valparaíso: Mensaje al país del Presidente de la República, Sebastián Piñera Echenique. Disponível em: [http://www.camara.cl/camara/media/docs/discursos/21mayo_2010.pdf] Acesso: 22 maio 2015.

RIGGIROZZI, Pia; TUSSIE, Diana. (2012). The Rise of Post-Hegemonic Regionalism. The Case of Latin America. New York: United Nations University Series on Regionalism, Vol. 4, 2012, XVII.

RÍOS, Sandra; VEIGA, Pedro da Motta P. (2007). O regionalismo pós-liberal, na América do Sul: origens, iniciativas e dilemas. SANTIAGO: CEPAL. Disponível em: [http://repositorio.cepal.org/bitstream/handle/11362/4428/S2007612_p t.pdf?sequence=1] Acesso em: 15 jun. 2015.

SANAHUJA, José Antonio. (2010). La construcción de una región: Suramérica y el regionalismo posliberal. In: Una región en construcción: Unasur y la integración en América del Sur. Cienfuegos, Manuel y José Antonio Sanahuja (eds.) Barcelona: CIDOB, 2010, pp. 87-134. 
(2009). Del 'regionalismo abierto' al 'regionalismo post-liberal'. Crisis y cambio en la integración regional en América Latina. Anuario de la integración regional de América Latina y el Gran Caribe. Coordinadora Regional de Investigaciones Económicas y Sociales-CRIES. Buenos Aires, v. 7, p. 11-54. Disponível em: [http://www.iadb.org/intal/intalcdi/PE/2009/02450.pdf]. Acesso em: 20 jun. 2015.

SERBIN, Andrés. (2010). Regionalismo y soberanía nacional en América Latina: los nuevos desafíos. In: Documentos CRIES, № 15, Buenos Aires: CRIES, 2010. Disponível em: [http://www.cries.org/wp-content/uploads/2010/09/Documentos-15-web.pdf] Acesso em: 11 jun. 2015.

SILVA, Fabricio Pereira. (2011). Vitórias na Crise: Trajetórias das esquerdas latino-americanas contemporâneas. Rio de Janeiro: Ponteio. 